Provided for non-commercial research and education use. Not for reproduction, distribution or commercial use.

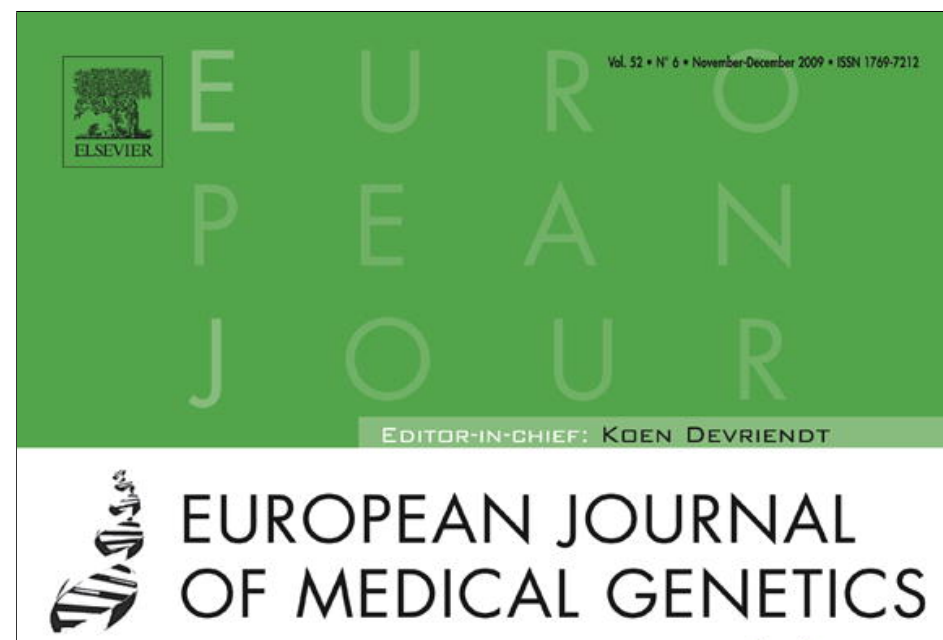

FDRMERLY KNDWN AS ANNALES DE GÉNÉTIQUE.

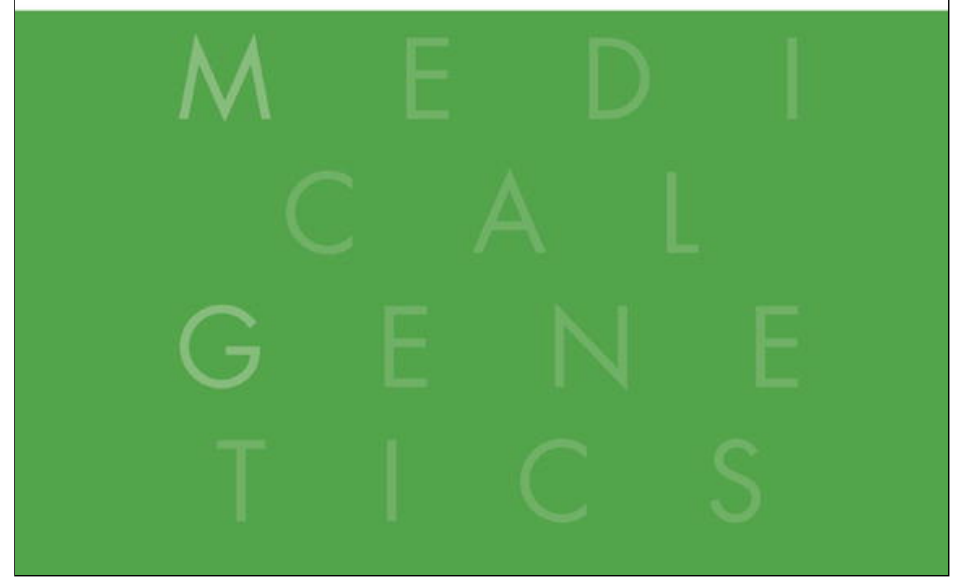

This article appeared in a journal published by Elsevier. The attached copy is furnished to the author for internal non-commercial research and education use, including for instruction at the authors institution and sharing with colleagues.

Other uses, including reproduction and distribution, or selling or licensing copies, or posting to personal, institutional or third party websites are prohibited.

In most cases authors are permitted to post their version of the article (e.g. in Word or Tex form) to their personal website or institutional repository. Authors requiring further information regarding Elsevier's archiving and manuscript policies are encouraged to visit:

http://www.elsevier.com/copyright 
Original article

\title{
The use of diagnostic collections of DNA for research: Interviews at the eight Belgian centers for human genetics
}

\author{
Kristien Hens $^{\mathrm{a}, *}$, Herman Nys ${ }^{\mathrm{a}, 1}$, Jean-Jacques Cassiman ${ }^{\mathrm{b}, 2}$, Kris Dierickx $^{\mathrm{a}, 3}$ \\ ${ }^{a}$ Katholieke Universiteit Leuven, Centre for Biomedical Ethics and Law, Kapucijnenvoer 35/3 Box 7001, 3000 Leuven, Belgium \\ ${ }^{\mathrm{b}}$ Katholieke Universiteit Leuven, Departement Menselijke Erfelijkheid, Herestraat 49 Box 602, 3000 Leuven, Belgium
}

\section{A R T I C L E I N F O}

\section{Article history:}

Received 12 February 2010

Accepted 4 July 2010

Available online 30 July 2010

\section{Keywords:}

Research ethics

Interviews

Stored DNA

Consent

Professional ethics

\begin{abstract}
A B S T R A C T
The attitudes towards the reuse for research of biological samples that were gathered in a diagnostics context have changed over the last years. A few decades ago, people would not hesitate to use such samples without explicit consent. Then, in conjunction with a move towards a stress to personal autonomy in bioethics, many would argue that written consent for such secondary use is necessary. Not much is known about the actual practices with regard to this subject. We have interviewed spokespersons of all eight Belgian centers for medical genetics, and have found that they would all adhere to the latter stream of thought. As such, they would not use diagnostic DNA for research purposes without written consent. Recently, however, international guidelines have moved towards the concept of presumed consent for diagnostic samples. There is agreement that patients and donors should be informed about possible research uses, and should be given the opportunity to opt out, but there is no need for explicitly written consent to be able to use these samples. Extracted DNA may fall under the same regime as other tissue that is gathered in a diagnostic or surgical context in university hospitals. Such policy satisfies both the requirement of respect for donor's autonomy as well as the requirement of using research resources sensibly and is backed by international guidelines and opinions.
\end{abstract}

(c) 2010 Elsevier Masson SAS. All rights reserved.

\section{Introduction}

Biological samples and extracted DNA gathered in the context of diagnosis or in the context of studies for specific diseases can be useful for research purposes, e.g. for large database studies $[7,8]$. Centers for medical genetics worldwide store huge collections of extracted DNA gathered in the context of diagnostics and genetic testing. There is much uncertainty, however, under which circumstances these diagnostic collections could be used for fundamental research, and whether they would fall under the same regime as the general policy of the associated hospital with regard to tissue samples and leftover bodily material. Most of this uncertainty has to do with the type of consent that should exist for the use of DNA samples for research and whether consent is truly needed. The attitudes towards the reuse for research of biological

\footnotetext{
* Corresponding author. Tel.: +32 16 336958; fax: +32 16336952.

E-mail addresses: kristien.hens@med.kuleuven.be (K. Hens), herman.nys@med. kuleuven.be (H. Nys), jean-jacques.cassiman@med.kuleuven.be (J.-J. Cassiman), kris.dierickx@med.kuleuven.be (K. Dierickx).

1 Tel.: +32 16 336949; fax:+32 16336952 .

2 Tel.: +32 16 345860; fax: +32 16345997

3 Tel.: +32 16 336955; fax: +32 16336952 .
}

samples that were gathered in a diagnostics context have changed over the last years. A few decades ago, people would not hesitate to use such samples without explicit consent. Then, in conjunction with a move towards stressing the importance of personal autonomy in bioethics, many would argue that written consent for such secondary use is necessary $[6,11]$.

An example of the arguments for and against requiring consent for the use of archived samples, originally gathered during diagnostics procedures or therapeutic surgical procedures can be found in Van Diest and Savulescu's debate 'No consent should be needed for using leftover body material for scientific purposes. For and against' [6]. Paul Van Diest, who thinks consent is not strictly needed, remarks that consent is implicit in the consent obtained from patients for the diagnosis and treatment of their disease. Such material is kept in the benefit of the patient: new DNA tests are constantly being developed and may shed new light on the genetic condition the patient suffers from. But such collections are also a rich source of teaching and research materials. He thinks that recontacting patients for informed consent for research would take too much time and money, whereas the research itself might ultimately benefit patients as well. According to Van Diest, all issues raised why such tissues should not be used can be easily solved: researchers should make sure enough DNA is left for future 
diagnosis and coded or anonymous samples should be used for research. It is also only fair that people are told that their tissues might also be used for research, but this need not be in the form of formal consent.

Julian Savulescu [6], however, thinks consent is needed to use leftover tissue for research. He states that research on tissue can harm patients by disclosing health or other information resulting in discrimination in employment or insurance, that patients may have values regarding research, especially commercial or genetic research and that seeking consent promotes public confidence in medicine and research, prevents exploitation, and regulates the behavior of researchers.

We found no studies investigating the consent practices of institutions storing DNA samples for diagnostic purposes. Therefore, we investigated these practices in all the Belgian Centers for Medical Genetics (CMG's). We interviewed representatives of the eight centers on the topics of the nature of their collections, and consent practices for the use for research of tissue that was originally gathered in a research context. As most literature on the topic of stored tissue samples deals with large population based studies, our study is unique. First, it queries the practices in an entire country. Secondly, the specific context, that of centers where diagnostics and research are closely interwoven and legally regulated, such as is the case in Belgium, can shed a unique light on the matter. Hence, our purpose is twofold. We first give an overview of the working and general practices of the Belgian Centers for Medical Genetics to set the scene. Secondly, we discuss the practices with regard to the use of DNA in diagnostics collections for research, and the perceived barriers to doing so.

Belgium has eight centers for human genetics, which are recognized as per the royal decree of 14 December 1987 (Table 1). This royal decree defines a center for human genetics as follows: A center for human genetics is a center that does diagnosis on the inheritability of certain malformations and abnormalities, mental as well as physical, on the nature of these malformations and abnormalities and on the carrier status of genetic characteristics. Only centers that are recognized by the Minister of Public Health are allowed to operate. Such recognition is dependent on certain conditions. For example, the center should be dependent on a university hospital with a faculty of medicine, only one center for human genetics per university hospital is allowed, and the center is led by a medical doctor with a specific education. At least two full

Table 1

\begin{tabular}{|c|c|c|}
\hline University/Name of institution & Language & Address \\
\hline Vrije Universiteit Brussel & Dutch & $\begin{array}{l}\text { UZ VUB } \\
\text { Laarbeeklaan } 103 \\
1090 \text { Jette }\end{array}$ \\
\hline Katholieke Universiteit Leuven & Dutch & $\begin{array}{l}\text { Campus Gasthuisberg } \\
\text { Herestraat } 49 \\
3000 \text { Leuven }\end{array}$ \\
\hline Universiteit Antwerpen & Dutch & $\begin{array}{l}\text { Prins Boudewijnlaan } 43 \\
2650 \text { Edegem }\end{array}$ \\
\hline Universiteit Gent & Dutch & $\begin{array}{l}\text { UZ Gent } \\
\text { De Pintelaan } 185 \\
9000 \text { Gent }\end{array}$ \\
\hline Université de Liège & French & $\begin{array}{l}\text { Sart Tilman } \\
\text { Bâtiment B } 35 \\
4000 \text { Liège }\end{array}$ \\
\hline Université Libre de Bruxelles & French & $\begin{array}{l}\text { Campus Erasme } \\
\text { Route de Lennik } 808 \\
1070 \text { Bruxelles }\end{array}$ \\
\hline Université Catholique de Louvain & French & $\begin{array}{l}\text { Cliniques Universitaires St-Luc } \\
\text { Avenue Hippocrate } 10 \\
1020 \text { Bruxelles }\end{array}$ \\
\hline $\begin{array}{l}\text { Institut de Pathologie et de } \\
\text { Génétique }\end{array}$ & French & $\begin{array}{l}\text { 25, Avenue George Lemaître } \\
6041 \text { Gosselies }\end{array}$ \\
\hline
\end{tabular}

time medical doctors should be employed by the center. The center should be able to supply a diagnosis or help in finding a diagnosis and should give all possible psychological and moral assistance to those concerned. They should also perform genetic research and collect data for epidemiological purposes. The Institut de Pathologie et de Génétique (IPG) is the only center not directly associated with a university hospital. The royal decree specifies that centers that were subsidized before 1st of January 1988 could also apply for recognition even if they do not completely meet the above quoted exceptions. The IPG is the sole example of this exception.

\section{Material and methods}

We conducted semi-structured interviews with spokespersons of the eight centers for medical genetics in Belgium from January 2009 till July 2009. The interviewees consisted of five clinical geneticists and three geneticists with laboratory responsibility. Representatives were contacted by sending out an email with the interview guide to the head of the center of medical genetics, who would then do the interview him or herself or appoint someone to do the interview. Each interview took between $40 \mathrm{~min}$ and $1 \mathrm{~h} 30$. The language of the interviews was either French or Dutch, depending on the mother tongue of the interviewee.

We developed an interview guide, containing questions about the profile of the institute and the collection and consent procedures (Table 2). This interview guide was reviewed by four members of the Leuven Center for Human Genetics and revised based on their suggestions. Our approach was a semi-structured interview rather than a structured one as we wanted to pick in on interesting remarks and finding during the interview. Kristien Hens $(\mathrm{KH})$ was the interviewer in all eight cases; Kris Dierickx (KD) was assistant interviewer at the first interview.

Audiotapes of the sessions were transcribed but not corrected for grammar, in order to capture the oral nature of the discussion. We used NVivo 8 to code the transcripts [1]. First, the texts were coded in eight cases, reflecting the different centers. Then we did a detailed topical coding. We then combined the codes into broader thematic categories. $\mathrm{KH}$ did an extra coding on paper to fully grasp the themes of the interviews. As a last pass, we did a fresh coding to grasp common themes across the different topics. The texts were also checked for common themes independently by KH and KD. A few quotes are included as examples; these were translated from either Dutch or French in English. We interviewed six women and two men. Throughout this paper we shall use the pronoun 'she' when referring to the interviewee.

\section{Results}

In this section we discuss the findings based on our eight semistructured interviews. We shall first discuss the types and profile of the collections in the different institutions. Next we shall discuss the issue of reusing collections for research and consent to such research (Table 3).

\section{Profile of the institute and the collection}

The total number of staff members working at the different CMG's varies between 40 and 150 . Three centers quoted the number of 80 staff members. The centers had between 3 and 7 clinical geneticists. Most of the people in the center would combine a clinical function and a research function, with the former as the main task.

With regard to the types of collections, the vast majority of DNA stored in the CMG's is stored for diagnostic purposes. All centers keep extracted DNA and cell lines; the original tissues are not 
Table 2

Summary of questionnaire.

\begin{tabular}{ll}
\hline Themes & Questions \\
\hline Profile of institution & How many people are working at your institution? How many are clinical geneticists? How many are researchers? \\
Profile of collection & Which types of biological materials are stored? Do you have collections solely used for research? \\
& How long do you store biological samples?Do you keep samples of deceased persons? \\
& $\begin{array}{l}\text { Do you keep links between family members? How is the } \\
\text { storage of biological materials funded? }\end{array}$ \\
Reuse of diagnostic samples & Would you reuse samples gathered in a diagnostics context for \\
& research purposes? \\
Informed consent & Do you ask for written informed consent for storage of biological samples? Do you ask for specific consent or for \\
& general consent? Do donors or patients have the right to withdraw their sample from the collection?
\end{tabular}

stored. They typically do not have big research collections. The research collections that were mentioned were disease-specific collections linked to special research interests of the clinical geneticists. For example, one center had a biobank for research on obesity with biological materials from healthy children. Another center was setting up a database with healthy controls with the help of an occupational health officer and was planning to set up a cohort for positive controls as well. The representative of one center was very clear on the fact that she did not consider the diagnostics collection as a real bank, and hence, regulations concerning biobanks would not apply. A representative of another center stressed the fact that the diagnostics and research collections were completely separate, the latter containing volunteers that had given written informed consent. Overall, diagnostics and research were kept separate in all centers, although they may or may not be physically managed in the same location.

The funding of the storing and managing of DNA collections at the Belgian CMG's was done through the consultations at the hospital and was hence not limited in time. Two centers mentioned the (limited in time) funding of specific research projects through funding bodies such as the FWO (Research Foundation Flanders), but one representative stated that such limited funding was typically not sufficient to accommodate for DNA storage. Additional research projects linked with the CMG's are hence primarily funded through the cash flow from the hospitals.

All centers store links between family members, especially in a diagnostics context. In this respect, one center mentioned that their software would allow for extensive searches in family trees. If samples are gathered for research purposes only, this is not always done, if it is not relevant to the research. With regard to other additional data, for the diagnostics collections, a medical file is kept, but environmental and lifestyle data that are not relevant for diagnosis are not kept systematically. If a research project requires such additional information, however, it is possible that the researcher gathers this kind of information.

A most controversial issue was the length of storage of DNA samples. All centers had kept their DNA samples for diagnosis since the beginning of extraction, al least 20 years ago. Four interviewees stated that they did so because they were unsure whether they were actually legally allowed to throw anything away. One interviewee said it would be too much work to check which ones should be destroyed and which ones kept, and therefore they were kept as long as space permits.

One representative, a clinical geneticist, stated the clash between practicality and potential clinical relevance as follows:

In principle you have to keep that DNA of course forever... Sooner or later there has to be a limit because we shall have lack of space... But I think it is also unethical if you have that material to throw it away. Especially with genetic tests, these are family histories. Let us say you have material that was stored in 1968 , from uncle $\mathrm{X}$, who has a genetic disease. And now the greatniece wants to inform about the likelihood of passing the risk to her children. If you no longer have the material of the uncle, you cannot check that, because he could be deceased. And that, I think, is extremely unethical.

In the same context, another interviewee stated that it is all the more important to keep materials from deceased persons. They might have died from a genetic condition which was untraceable at the time of death, but for which a genetic test could have been devised in the mean time. Information from that person's DNA could be relevant to family members. Moreover, the centers acknowledge that they often had no way of knowing that a patient whose DNA is in the collection had died.

\section{Reuse of existing DNA collections and consent}

The Belgian Centers for Medical Genetics primarily store DNA for diagnostic purposes. The primary aim of most of the collections is for the benefit of the patients who donated the DNA. Some of these diagnostic uses may be on the boundary of research: if there was no test available for a genetic condition when a sample was taken, these samples could be used to validate new tests when they become available. Hence, such research serves a diagnostic purpose as well.

No explicit written consent is asked for storage of DNA samples for diagnostic purposes. One clinical geneticist mentioned that people are told that DNA is kept, and that people always regard this as a reassurance, as it could be useful for their children or family members. She made a comparison with RX pictures that are taken for diagnostic purposes:

Table 3

Themes.

\begin{tabular}{ll}
\hline Themes & \\
\hline Profile of institution & Centers had between 40 and 150 collaborators. \\
Profile of collection & Diagnostics and research collections were kept separate \\
& All centers kept extracted DNA indefinitely, also DNA from deceased persons. \\
Reuse of diagnostic samples & Written informed consent was not asked for storage of samples in a diagnostic context \\
& Centers would not reuse diagnostic samples for research without written consent \\
Informed consent & $7 / 8$ used specific consent for research \\
& $1 / 8$ had a standard informed consent form \\
& All centers would agree to a request for withdrawal of a sample from their research and diagnostics collections.
\end{tabular}


An oral [consent], especially because it is for clinical purposes. You can compare it to an RX picture that was taken from you, you assume that they keep it but you do not give written consent for the fact that they keep those images.

The collection of samples that was kept for diagnostic purposes was not used for research purposes without written consent. Only one representative thought that in case of completely anonymized samples, that were separated from the diagnostics collection, they would maybe consider having research on these samples approved by the hospital's ethics committee, but she was uncertain whether this had already happened. Two other representatives were explicit that their ethics committee would not allow research on samples for which there was not explicit written consent for that research. All interviewees thought that, should part of the collection prove to be very interesting for research, they would try to recontact the patients via the clinical geneticist who sees the patient for written consent. Or, when they would know beforehand that a sample of a patient would be particularly interesting for research, the clinical geneticist would solicit written consent at the time of the genetic consultation. One clinical geneticist we interviewed expressed this as follows:

In any case, our ethics committee is very vigilant: storage of DNA [in case of research] is generally done in the context of a research project with an ethics committee approval. Our ethics committee does not really like that we would stock for future unspecified research, it has to be done with a specific aim. If we would want to use our collection for other reasons we should have foreseen it in a formal consent beforehand, but it is a bit difficult to say we shall probably do something else... Therefore our ethics committee does not like it. In any case we should contact the people that have accepted to give us their DNA.

The consent forms themselves were mostly created or adapted individually for each research study, although some representatives mentioned that they were in the process of creating a more standard form for the entire center, and one already had a standard consent form that is used by all clinical geneticists of the center. This consent form is analyzed in Table 4. Consent was given for research on specific conditions, although one center used general consent for unspecified research for their collection of control samples.

With regard to the right to withdraw DNA from a collection, research or diagnostics, all representatives agreed that they would comply with a request of withdrawal. This however did not happen often, and most thought the situation to be quite hypothetical, as, especially in a diagnostic context, something that may be useful for a patient would be gone. Only two interviewees could remember a case were this was requested. One clinical geneticist stated that the opposite situation was more prevalent: she had cases where people insist on DNA being kept even if they did not have a diagnostic test themselves, so that their children would still have access to that information once they themselves were deceased. Seven centers stated that they would destroy the sample when asked. One person remarked that in the one case they had a request for withdrawal they decided to keep the sample but just not to use it any further. The reason for this was that if a sample is destroyed, diagnostic tests that were already done on it could no longer be validated.

\section{Discussion}

The eight Belgian Centers for Medical Genetics are primarily diagnostic institutes, with some research activities. As diagnostic centers, they have large collections of DNA samples, which, in principle, could also form a rich resource for research. However, our interviewees were reluctant to use the diagnostics collections for research. The main barrier quoted that there was no explicit written consent from the donors. Additionally, some stated that their ethics committee would never allow such research without such consent. Research was in this context understood by them as non-therapeutic research, having no direct benefit for the participants. However, in the specific context of these centers, the boundary between research and diagnostics seems to be often blurred. The storage of DNA serves both a diagnostics and research purpose that cannot easily be separated in certain cases. For example, stored DNA may be used to develop new diagnostic tests. Anecdotic evidence shows that in such cases, consent is not always sought from the donor, because such findings may still benefit the patient. Hence, the consent requirement seems in some instances to be linked to the benefit factor of research. The reluctance to reuse diagnostic samples for research was also linked to an uncertainty about the legal requirements, as we find also on other topics in this context, such as carrier testing on minors [2]. Also the overall tendency to keep samples forever is linked to this. This calls for clear legal guidance from the legislator's side and for a need to educate researchers and clinicians on the legal aspects.

For more general non-therapeutic research purposes, there seems to be a trend away from requiring explicit consent for research using existing collections of human tissue in literature and guidelines. Some authors have suggested frameworks that would allow for such research without consent [6]. Gert Helgesson, for example, has created an ethical framework for research on 'consentless' samples in clinical biobanks. He proposes that each research project should be preceded by a careful assessment by both the researchers themselves and an ethical review board (ERB) to ascertain predictable risks and burdens in relation to foreseeable benefits to the subject and others. He has developed consent routines for research on biobank samples where no consent was obtained or the consent was unclear, and thinks that, given proper ethical guidance, such samples may be used without new consent, under an opt-out regime [9]. He also thinks that deceased subjects may be included, because excluding them would create bias, except if the donor or his or her survivors explicitly requests the material is not used. Also Bathe and McGuire have a similar stance. They acknowledge the fact that archival tissue is a rich source for translational research and that recontacting donors may be unfeasible or unpractical. They think

Table 4

Analysis of one standardized consent form for research on and storage of DNA samples.

\begin{tabular}{ll}
\hline Themes & Elaboration \\
\hline Type of consent form & Written consent \\
$\begin{array}{l}\text { Scope of consent form } \\
\text { Scope of research }\end{array}$ & $\begin{array}{l}\text { Taking of DNA sample for research and storage } \\
\text { Genetic research that can aid the diagnosis or treatment of the illness of the patient or a family member } \\
\text { Information for patient }\end{array}$ \\
$\begin{array}{l}\text { Doctor has mentioned techniques; the fact that the study takes several years, that the DNA is stored, and which results such } \\
\text { research might have. } \\
\text { Medical data and confidentiality }\end{array}$ & $\begin{array}{l}\text { Data from medical file can be used. Mentions confidentiality. Does not mention identifiability of samples. Only the named } \\
\text { doctor or someone authorized by this doctor can access the information. }\end{array}$ \\
Right to withdraw & Patient has right to ask for the destruction of DNA \\
Return of results & Donor specifies whether they want to receive the results of the study. Nu further specification about the type of results. \\
\hline
\end{tabular}


that, when an ethics committee has assessed the purpose of the research, and that privacy concerns are addressed through proper coding, the requirement for informed consent could be waved [3].

Some empirical studies have pointed in this direction as well. For example, A study by Stegmayr has shown that is not unfeasible to recontact donors and the vast majority $(93,0 \%)$ would agree to give their blood samples for academic genetic research provided that an ethics committee had approved of the research. A majority of that was OK with general consent, $22 \%$ wanted to be informed of each research project [13]. This strategy would also agree with findings from a focus group study amongst the Belgian population [10].

In a review of international and national guidelines on the secondary use of archived biological samples, that were gathered for diagnosis or other research, Bartha Maria Knoppers found that many policymakers make a difference regarding the identifiability of samples, whether they are anonymized or not. They also reflect a move away from requiring an explicit reconsent for all secondary uses, provided other safeguards are in place, such as double-coding, anonymization and Research Ethics Board (REB) approval [11]. Also the Human Genome Project states that stored samples can be used if there is a general notification of such policy, the participant has not objected and the samples are coded or anonymized afterwards [5]. In the recent guidelines of the OECD on Human Biobanks and Genetic Research Databases [12], the possibility of a waiver of consent for existing collections is mentioned, when law permits and after review of an ethics committee:

In the situations of HBGRDs established from existing collections, the operators will need to consider whether the intended scope and purpose of the HBGRD and the intended research uses of the human biological materials and/or data are consistent with the original informed consent. Where the intended scope of the HBGRD or its intended uses are not within the ambit of the original informed consent or none was obtained, for example, the human biological materials and/or data may only be used if a new consent is obtained or if a waiver of consent is obtained from a research ethics committee or an appropriate authority, in accordance with applicable law and ethical principles.

On a European level, in the Recommendation of the Committee of Ministers to member states on research on biological materials of human origin [4] there are also provisions for the reuse of material for research.

1. Biological materials removed for purposes other than storage for research should only be made available for research activities with appropriate consent or authorization, or in accordance with the provisions of Article 22 paragraph 1.ii. Art 22.

1.i. If the proposed use of identifiable biological materials in a research project is not within the scope of prior consent, if any, given by the person concerned, reasonable efforts should be made to contact the person in order to obtain consent to the proposed use.

ii. If contacting the person concerned is not possible with reasonable efforts, these biological materials should only be used in the research project subject to independent evaluation of the fulfilment of the following conditions:

a. the research addresses an important scientific interest;

b. the aims of the research could not reasonably be achieved using biological materials for which consent can be obtained; and

c. there is no evidence that the person concerned has expressly opposed such research use.

This recommendation suggest that, for research projects that have been reviewed by ERBs and given proper governance and privacy protection of the collections themselves, diagnostics collections of DNA could be used for research purposes as well. Many hospitals nowadays use a notification policy for other types of leftover tissue such as surgical waste. They distribute folders explaining the fact that such tissue may be reused for research. Below is an example from the folder of one such hospital, which is given to patients upon admittance:

\section{Analysis of bodily material}

Bodily material that is left over after a diagnosis or surgery (leftover material) may be used for scientific research. Each such research should be preceded by a positive recommendation from the ethics committee of Hospital X. If you do not wish this to happen, you or your representative can refuse such use. You can discuss your refusal with the clinician responsible for removing the bodily material or with the chief of medical staff of Hospital X. (translated from Dutch).

Extracted DNA stored in centers for human genetics associated with these hospitals could fall under the same regime, although the perceived special status of DNA could form a barrier to the acceptance of such policy. For new samples the potential research use of samples can be discussed by the clinical geneticist when blood is taken. We think that such an approach would both be respectful for the donor as well as allow research to proceed, especially if it is accompanied with the right to withdraw samples at any time and provided participants and patients have the opportunity to be informed about the types of research performed at the hospital, if they do so wish.

The majority of our interviewees specified that they ask for specific consent for research. However, empirical research amongst donors has shown that many people do not mind giving broad consent [15]. And a recent study has shown that a majority would be willing to consider giving open ended consent for the use of blood left over from routine clinical tests in general practice to be stored and used later for medical research [14]. If research would take a turn away from the original condition or conditions the patient suffers from, or if the nature of research would change drastically (e.g. a complete genome sequence would be done), the donor should probably be recontacted. Also the OECD guidelines suggest that a relatively broader consent can be devised, provided that the participant understand and consent to participating on this broader basis; and $(b)$ additional safeguards are in place to ensure that the interests of the participant are protected. So, Ethics committees could be educated not to be too conservative on the one hand, and to be able to decide sensibly when research takes a turn that would require recontacting donors for consent.

We admit that our study has several limitations. First, our interviewees had different profiles, which means that they have different perspectives on the practices in their institutions. Second, as we used interviews rather than surveys, our data was not completely quantifiable. Third, as the interviewer was an ethicist, we can not be sure whether the answers given would be best practices rather than real practices. However, our study has shown that there is a strong ethical awareness amongst professionals working with diagnostic samples, and an overemphasis on consent.

\section{Acknowledgements}

This work was supported by GeneBanC, an EU-FP6 supported STREP contract number 036751 and FWO Flanders, project number G029107. We would also like to thank Liesbeth Vandevenne, Eric Legius and Gert Matthijs for their help and our eight interviewees for their time and willingness to share their knowledge. We would like to thank the anonymous reviewers for their comments. 


\section{References}

[1] P. Bazeley, Qualitative Data Analysis with NVivo. SAGE Publications, London, 2008

[2] P. Borry, L. Stultiens, T. Goffin, H. Nys, K. Dierickx, Minors and informed consent in carrier testing: a survey of European clinical geneticists, J. Med. Ethics 34 (5) (2008) 370-374.

[3] O.F. Bathe, A.L. McGuire, The ethical use of existing samples for genome research, Genet. Med. 11 (10) (2009) 712-715.

[4] Council of Europe, Recommendation Rec(2006)4 of the Committee of Ministers to member states on research on biological materials of human origin, 2006.

[5] M. Deschênes, K.C. Glass, G. Cardinal, B.M. Knoppers, Human genetic research, DNA banking and consent: a question of 'form'? Clin. Genet. 59 (4) (2001) 221-239.

[6] P.J. van Diest, J. Savulescu, No consent should be needed for using leftover body material for scientific purposes, For and Against. BMJ 325 (7365) (2002) 648-651.

[7] I. Ellis, Retained human tissues: a molecular genetics goldmine or modern grave robbing? A legal approach to obtaining and using stored human samples, Med. Law 22 (3) (2003) 357-372.
[8] M.G. Hansson, Ethics and biobanks, Br. J. Cancer 100 (1) (2008) 8-12.

[9] G. Helgesson, J. Dillner, J. Carlson, C. Bartram, M. Hansson, Ethical framework for previously collected biobank samples, Nat. Biotechnol. 25 (9) (2007) 973-976.

[10] K. Hens, K. Dierickx, Human tissue samples for research. A focus group study in adults and teenagers in flanders, Genetic Counseling 21 (2) (2010) 157-168.

[11] B.M. Knoppers, Ethical issues in secondary uses of human biological materials from mass disasters, J. Law Med. Ethics 34 (2) (2006) 352-365.

[12] Oecd, Oecd Guidelines on Human Biobanks and Genetic Research Databases, 2009 .

[13] B. Stegmayr, Informed consent for genetic research on blood stored for more than a decade: a population based study, BMJ 325 (7365) (2002) 634-635.

[14] S. Treweek, A. Doney, D. Leiman, Public attitudes to the storage of blood left over from routine general practice tests and its use in research, J. Health Serv. Res. Policy 14 (1) (2009) 13-19.

[15] D. Wendler, One-time general consent for research on biological samples, Br. Med. J. 332 (7540) (2006) 544-547. 